\title{
Surveying RFI for a new Brazilian Solar Spectroscope site
}

\author{
José R. Cecatto ${ }^{1}$, Paulo C. G. Albuquerque ${ }^{2}$, Ivan O. G. Vila ${ }^{3}$, \\ Alan B. Cassiano ${ }^{1}$, César Strauss ${ }^{1}$ and Francisco C. R. Fernandes ${ }^{4}$ \\ ${ }^{1}$ Astrophysics Division, National Institute for Space Research (INPE), \\ 12227-010, São José dos Campos, Brazil \\ email: jrc@das.inpe.br \\ ${ }^{2}$ Remote Sensing Division-INPE, 12227-010, São José dos Campos, Brazil \\ email: gurgel@ltid.inpe.br \\ ${ }^{3}$ Aerospace Electronics Division-INPE, 12227-010, São José dos Campos, Brazil \\ email: geier@dea.inpe.br \\ ${ }^{4}$ Institute of Research \& Development-Univap, 12244-000, São José dos Campos, Brazil \\ email: guga@univap.br
}

\begin{abstract}
Brazilian Solar Spectroscope (BSS) carry out high time (0.01-0.1 s) resolution solar spectral investigations within the frequency range $1-2.5 \mathrm{GHz}$ on a daily basis. At the moment, a new site is imposed to this facility. This site change became necessary due to both factors: the growing level of radio frequency interference (RFI) signals at actual site and requirements of rising up a new building at the BSS antenna location. We present results of RFI signals search at INPE-Cachoeira Paulista area as purpose to define a new BSS site.
\end{abstract}

Keywords. Sun: radio radiation; instrumentation: spectrographs; site testing

\section{Introduction}

Almost twenty years ago a radio spectrograph designed by Brazilian Solar Spectroscope

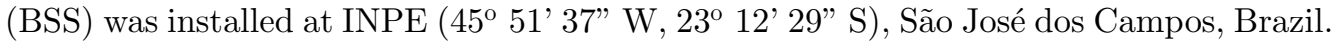
In its first phase, operated with narrow band $(1600 \pm 50 \mathrm{MHz})$ up to the starting of last solar cycle. By that time, the feeder was replaced. Then, BSS changed to operate in a broad band frequency range, 1-2.5 GHz (Sawant et al., 2001). Since then, it has been carried out several thousand hours of solar observation. Also, over four hundred groups of solar radio bursts have been recorded and used for research. However, during recent years, radio frequency interference (RFI) signals became disturbing to the frequency band of BSS acquisition data. In parallel to this, a plan to rise up a new building in the place of BSS antenna imposed the instrument moving to a new site. In this paper we briefly describe RFI measurements and results as a purpose to define a new site.

\section{Searching RFI signals and results}

The process to choose a new radioastronomical site is complex and requires to be taken into account for several important aspects. The main is the RFI signal level at the site. An ideal site is isolated from all RFI. In practice, as an ideal site is unavailable a place with the lowest acceptable level of RFI must be chosen. As this we mean detectable signals whose level is below the nominal operational level or which do not mask or disturb acquired data. Also important for a new radioastronomical site are (NSF, 1956):

i) antenna should be out the view and farthest possible any close-by human sources of noise which might disturbed the daily acquisition data. Comercial radio, mobile phone, 
and wireless internet broadcast antennas are the most common noise sources; ii) antenna should be out the view of any high tension power lines; iii) antenna should be in a valley surrounded by hills as much high and in as many directions as possible; iv) site should be in a remote place, tens of kilometers distant from big concentrations of people and industries; v) site should be in a place not subject to violent winds.

Fortunately, at BSS frequency band the atmospheric water vapour has a negligible influence. Other factors are also important, as known, availability of basic infra-structure as well as technical support, cost of site installation, and relatively easy access.

Following, a brief description of the method used to measure RFI in five places at INPE-Cachoeira Paulista campus.

Radio Frequency Interference - RFI. RFI signals constitute disturbing either intermittent or constant radio signals identified within the band on which operates a radiotelescope. Among we can mention mobile phone, illegal radio broadcasts, wireless internet, and GPS satellite signals. By convenience, a search of RFI signals in five places within INPE-Cachoeira Paulista (INPE-CP) area has been done, during November 2008, as a purpose to define a suitable radioastronomical site for the BSS frequency range (1000$2500 \mathrm{MHz}$ ). Chosen places have the following coordinates: Place 1: $22^{\circ} 41^{\prime} 32^{\prime \prime} \mathrm{S}, 45^{\circ} 00^{\prime}$ 56" W; Place 2: $22^{\circ} 42^{\prime} 07^{\prime \prime} \mathrm{S}, 45^{\circ} 00^{\prime}$ 20" W; Place 3: $22^{\circ} 40^{\prime} 56^{\prime \prime} \mathrm{S}, 44^{\circ} 59^{\prime} 12^{\prime \prime} \mathrm{W}$;

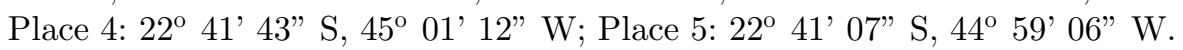

Figures 1 shows a satellite view of INPE-CP area with the five chosen places for RFI measurements numbered. Mounting used for the 5-6 days continuous measurements is composed of: a discone antenna, LNA with an approximately flat response in the above frequency range, portable spectrum analyzer (FSH6, $100 \mathrm{kHz}-6 \mathrm{GHz}$; R\&S) and a portable computer as shown in Figure 2. Figure 3 shows the results of measurements at the better place, numbered 3 . It has to be remarked that place presented the most clean spectrum with only one short duration (ms pulse) low level $(\leqslant-80 \mathrm{dBm})$ signal recorded at $1875 \mathrm{MHz}$ during one day of a 5-6 days period of measurements.

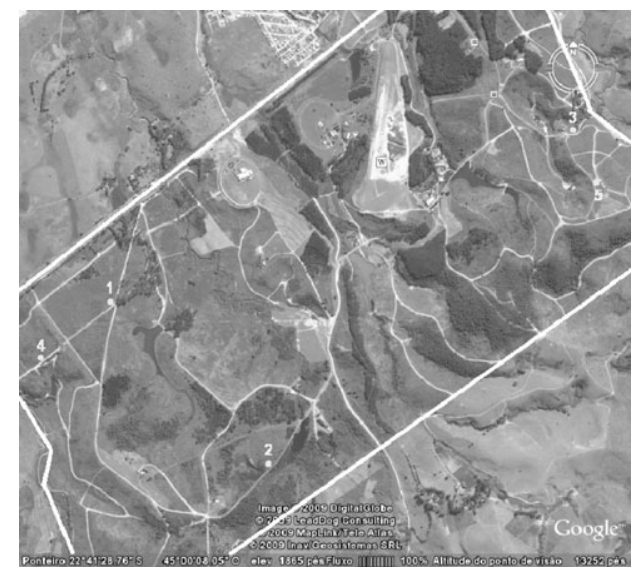

Figure 1. Satellite view (Google Earth, 2009) of INPE-Cachoeira Paulista (INPE-CP) area showing the five numbered places where RFI measurements have been done.

\section{Discussions and conclusion}

Defining a new radioastronomical site is a complex task which requires definite rules and care during the search process. Main rule refers to the existence of RFI signals 


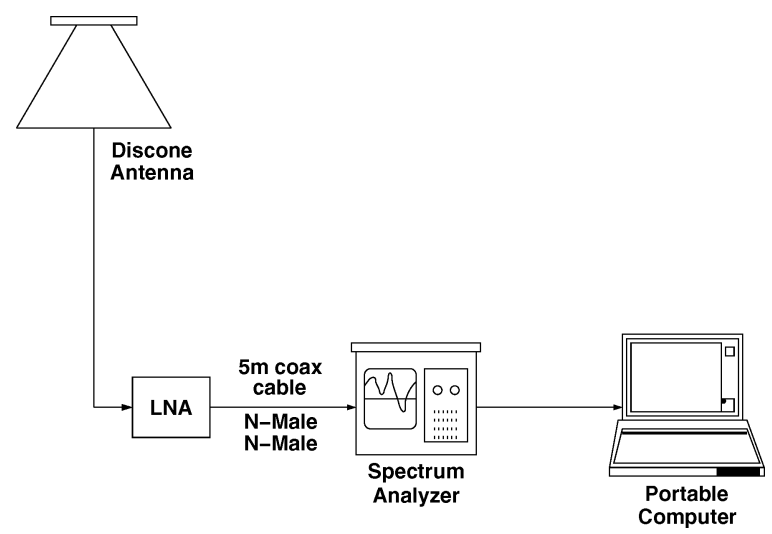

Figure 2. Mounting used for RFI measurements at INPE-Cachoeira Paulista.
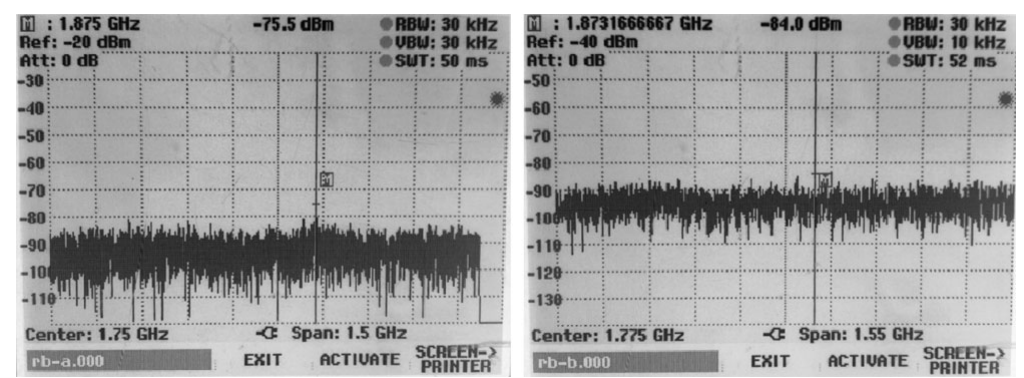

Figure 3. Measurements of RFI obtained on place 3 showing the lowest local level of RFI signals down to $-80 \mathrm{dBm}$.

within the radiotelescope operational frequency range in a level for which the instrument operation becomes disturbed. Also, it can be detected by the radiotelescope harmonics of lower frequencies corresponding to some strong signal at a particular fundamental frequency. A classical one is mobile phone signal at 800-900 MHz. This rule has been taken into account. Then, by convenience as our first approach we carried out a continuous 5-6 days search for RFI signals in five places within INPE-CP area. Our measurements indicate three places with open horizon or higher altitude present RFI which can disturb BSS operation. Other two places are relatively quiet. However, one is subjected to strong wind, has hills just on the West side and implies high cost on infra-structure installation. Last place fulfilled the requirement of low-level RFI $(\leqslant-80 \mathrm{dBm})$ associated to other requirements. Then, in principle even non-ideal that place within INPE-CP area seems to be adequate for a radioastronomical site. Details about all other aspects mentioned above relative to the definition of a new BSS site will be published somewhere else.

\section{Acknowledgements}

We acknowledge CNPq by Grant 475723/2004-0, INPE by financial-technical support.

\section{References}

NSF-Associated Universities Inc. 1956, Planning document for Establishment and Operation of a Radio Astronomy Observatory, NRAO Miscellaneous Unnumbered Internal Reports, 72p.

Sawant et al. 2001, Solar Phys., 200, 167. 